\section{STORAGE, SECURITY, AND DISPOSAL}

To the editor:

Approach opioid counseling on securing your prescriptions the same way you would you approach other valuables in your home, like jewelry or cash. There's no shame in helping protect those items, and the same holds true for your pain medications. Part of our patient counseling should always include the discussion of treating prescription opioids like our jewelry, cash or other valuables, which means keeping them in a secure place. Safe medication storage can mean keeping them under lock and key, if necessary. In 2013, findings from the Partnership Attitude tracking Study, sponsored by Metlife foundation, showed that one in four teens has misused or abused a prescription drug at least once in their lifetime. In these cases primary source for the medicines they misuse was not a drug dealer - it is friends, their home medicine cabinet or their friends' home medicine cabinet. ${ }^{1}$

Many clinicians are concerned that patients and family members are not given, or do not heed, instructions about safe use and storage of controlled substances. A recent survey showed that perceived risk for opioid diversion at home was only 10.8 percent, and 50 percent of patients reported receiving no information on safe opioid storage and/or disposal from health care providers. Similarly, opioids were stored in a locked location by 24 percent of patients, with the primary reason being "not worried about anyone taking medication." In addition, among patients with unused opioids, 17.9 percent did not dispose of their medication, with the chief reason being "save for future personal need."

Five basic, common-sense counseling tips for our patients. $^{3}$

1. Store opioids in a locked container.

2. Keep opioids in their original package.

3. Keep opioids out of children's reach.

4. Do not share your medication.

5. Safely dispose of unused pills.

Patients who received counseling about opioid storage and/or disposal were significantly more likely to keep their medication in a locked location than those not counseled: 39.2 percent versus 8.8 percent. $^{2}$ Patients who perceived any risk for opioid diversion in their home were also much more likely to store their opioids in a locked location than those who saw no risk or were uncertain: 51.9 percent versus 20.6 percent. ${ }^{2,4}$

According to the Drug Enforcement Administration (DEA) standards, proper, safe disposal requires controlled substances to be rendered "non-retrievable," this means that it is impossible for the controlled substance to be reconstituted and misused. Additionally, the method used must not be able to be reversed. The DEA has not established a single method for the destruction of controlled substances, but the way that the drug is destroyed must render the controlled substance nonretrievable.

Drug take-back programs have existed for more than a decade. However, many were hampered by the inability of pharmacies to accept the return of controlled substances, which are drugs that have some potential for abuse. Congress passed the Secure and Responsible Drug Disposal Act of 2010 in response to nonmedical prescription drug use and the overdose epidemic. This law directed the DEA to develop rules and regulations that would make it easier for communities to organize take-back events and easier for consumers to participate in these programs. Before this, it was illegal to collect controlled substances.

Members of the public may search for an Authorized Collection Site at https://apps.deadiversion.usdoj.gov/ pubdispsearch to find a collection receptacle location near them.

On September 8, 2014, the DEA issued a final rule regarding the disposal of pharmaceutical controlled substances. The new rule opens up options for disposal, to include expanded use of the mail, secure drop boxes, and other disposal systems. The DEA has held drug disposal or "Take Back" days approximately every six months that have resulted in millions of pounds of prescription drugs being properly disposed of. Pharmacies, state and local governments, and other nonprofit organizations now have an opportunity to build upon the DEA's efforts and develop ongoing disposal programs. Local communities are best positioned to develop disposal programs that can best meet their needs and be in compliance with local environmental regulations. 
Mail-back programs allow consumers to put their unwanted medications in a special package that is shipped back to a DEA authorized collector, which then processes the destruction of the drugs on site. If a pharmacy makes mail-back packages available, it does not need to modify its DEA registration (unlike providing a drop-box, which does require modifying registration). A drawback of this approach is that the consumer often bears the cost of the mail-back package.

Another approach is the use of specially designed packages that a consumer can use to neutralize the drugs and render them nonretrievable. An advantage of this approach is that it can be implemented by consumers directly. The next two approaches are not recommended, but are preferable to simply putting unwanted medicines in the garbage or keeping them in the home. However, the downsides of these approaches make the need for an effective, community-based safe drug-disposal program all the more pressing.

If a take-back program is simply not feasible in your community, consumers can dispose of unwanted drugs through the following steps:

1. Remove labeling from the pill bottle.

2. Do not crush the pills or open capsules.

3. Mix the drugs with an unpleasant substance, such as kitty litter or coffee grounds.

4. Put the drugs and unpleasant substance in the garbage separate from the pill bottle.

For most drugs, flushing is not recommended. Flushed drugs_-especially controlled substances_can damage the environment when they hit the water supply. As with mixing, consumers should remove their personal information from pill bottles before they are thrown out.

The federal regulations have been written to allow innovations in the way that drugs can be collected and destroyed. However, any method of destruction used to destroy collected controlled substances must render the controlled substances nonretrievable.

In summary, we need to talk to our patients about safe use of prescription opioids. Remind them continually that medications should be stored out of reach of children and in a safe place. Finally have the discussion about an appropriate way to dispose of expired, unwanted and unused medications.

Robert W. Hutchison, Jr., PharmD, BCACP Clinical Associate Professor of Pharmacy Practice

Department of Pharmacy Practice Round Rock, Texas

\section{REFERENCE}

1. Partnership for Drug-Free Kids: The Partnership Attitude Tracking Study: Teens and Parents 2013. Available at http://www.drugfree.org/up-content/uploads/2014/07/PATS-2013FULL-REPORT.pdf Accessed September 16, 2019.

2. Kronemyer B: Clinician counseling on opioid storage, disposal lacking. Pain Medicine News. September 10, 2019. Available at https://www.painmedicinenews.com/Primary-Care/Article/0919/Clinician-Counseling-On-Opioid-Storage-Disposal-Lacking/ 55843 Accessed September 10, 2019.

3. Robeznieks A: 5 tips for safely storing opioids at home. American Medical Association. Available at https://www.amaassn.org/delivering-care/opioids/5-tips-safely-storing-opioidshome. Accessed September 10, 2019.

4. A Healthier Michigan: The Dangers of Sharing Medicine. February 1, 2015. Available at www.ahealthiermichigan.org/ 2015/02/01/the-dangers-of-sharing-medicine/ Accessed September 16, 2019. 